\title{
Effect of renewable energy sources integration on the optimal coordination of directional over-current relays in distribution system
}

\author{
Lazhar Bougouffa ${ }^{1}$, Abdelaziz Chaghi ${ }^{2}$ \\ ${ }^{1}$ Department of Electrical of Engineering, Faculty of Technology, University of El-Oued, Algeria \\ ${ }^{2}$ LSP-IE Research Laboratory, Department of Electrical of Engineering, Faculty of Technology, \\ University of Batna 2, Algeria
}

\section{Article Info}

Article history:

Received Jan 31, 2020

Revised Feb 19, 2020

Accepted Mar 20, 2020

\section{Keywords:}

Distribution system DOCRs

Dual simplex method

Renewable energy sources

\begin{abstract}
The demand for power electricity is growing fast and one of the main tasks for power engineers is to generate electricity from renewable energy sources (RES). Nevertheless, problems arise when the new generation is integrated in the power distribution network. Under this condition, the main purpose in this paper, an investigation of the effect of RES integration on the optimal coordination of directional over-current relays in distribution system, a dual simplex optimization algorithm has been presented to determine the coordination of directional over-current relays (DOCRs). The system used to check the efficiency of the optimization algorithm which is IEEE 33-bus models. The analysis is performed in MATLAB software environment.
\end{abstract}

This is an open access article under the $\underline{C C B Y-S A}$ license.

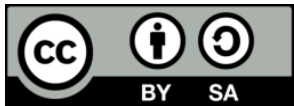

\section{Corresponding Author:}

Lazhar Bougouffa,

Department of Electrical of Engineering,

University of El-Oued,

PO BOX 789, 39000, El-Oued, Algeria.

Email: bougouffa-lazhar@univ-eloued.dz

\section{INTRODUCTION}

The worldwide demand for electricity continues to grow even as energy conservation measures and advances in power conversion efficiency reduce the consumption of individual loads. To feed the energy appetite of the world, renewable energy technologies are becoming feasible and offer alternative generation options that enable consideration of the impact on the environment and other social and economic factors [1]. The integration of renewable energy sources (RES) to the distribution network has numerous advantages. However, some problems in the coordination of protection devices will occur, due to changes in value and direction of power flow (under normal operation) and short-circuit current levels in different points (under fault conditions). The impact of RES on protective coordination depends on size, location and technology type of RESs. Therefore several ideas have been introduced as possible solutions to overcome the over-current $(\mathrm{O} / \mathrm{C})$ relay coordination problem in systems with $\mathrm{DG}$ [2].

The main objective of this study is to determine the optimal coordination of DOCRs in distribution system with renewable energy sources. The specific objective is to investigate the effect on fault current when installing RES in radial system and determine the new setting of the DOORs. Diverse methods have been reviewed by researchers in the past for optimal coordination of DOCRs, with distribution generation insertion in distribution system and FACTS diverse [3]. The authors in [4, 5] investigate the impacts on fault current when installing distributed generation on a radial system as well as the effect of the TCSC on the inverse definite minimum time (IDMT) directional over-current relay in distribution system. 
In this paper, the problem of determining the optimum values of TDS of DOCRs had been formulating. The dual simplex optimization method with proposed algorithm is used to determine optimum values of TDS. The case studies with a 33-bus system with 32 DOCRs and 2 RES are presented to illustrate the proposed method. Based on the coordination results obtained in this research, the proposed dual simplex optimization algorithm can be used to calculate the settings of the directional over current relays in a distribution network with distributed generation. The proposed algorithm has shown to have the ability to maintain selectivity between the primary relays and backup relays.

\section{DISTRIBUTION SYSTEM DESCRIPTION}

Renewable energy sources in power systems is one of attractive phenomena in power industry and it is no dispatch energy. With the presence of DGR units in distribution systems, its function would generally be changed and it would variously be affected by these units. One of the most important effects of these units is on distribution systems protection. Since the number of DGR units not only can be varied but also has a great deal of wide spread, distribution systems protective devices manner is completely changed with the presence of distributed generation.

RES units are electrical energy sources which are connected to distribution systems and in comparison with the large scale power stations, have a lower generation capacity and also have a lower starting cost. There are some cases in which the use of RES should be paid attention such as: economical problems in power stations developing, high efficiency of these sources, decreasing of environmental pollution, increasing of power quality, decreasing of loss in distribution systems, improvement of voltage profile and so one [6]. The majority distributed generators (DGs) are defined as renewable energy sources apply to the notion of generating power using a set of small sized generators that produces power at low voltage levels and usually uses alternative fuel. Distributed generators resources have been categorized as:

- Micro $(-1 \mathrm{~W}<5 \mathrm{~kW})$,

- Small $(5 \mathrm{~kW}<5 \mathrm{MW})$,

- Medium (5 MW<50 MW),

- Large (50 MW<300 MW).

The RESs are mainly designed to be connected directly to the distribution network near load centers. There are several types of DGRs in the market. Some are conventional such as the diesel generators and some are new technologies such as the micro-turbines. The major DGR alternatives are described briefly in the reference [7].

\section{OPTIMAL COORDINATION OF DIRECTIONAL OVER-CURRENT RELAYS IN DISTRIBUTION SYSTEM}

The current/time tripping characteristics of IDMT (inverse definite minimum time) relays may need to be varied according to the tripping time required and the characteristics of other protection devices used in the network. For these purposes, IEC 60255-3 defines a number of standard characteristics to find the over-current relays operating times which is defined by (5) and are indicated in Table 1. Typically, the inverse time over-current relay (OCR) consists of two elements, an instantaneous unit, and a time dependent unit. The time dependent unit has two values to be set, the Pickup current value (IP), and the time dial setting (TDS). The pickup value is the minimum current value for which the relay operates and the time dial setting defines the operating time $(\mathrm{T})$ of the device for each current value. Normally, the characteristics of the directional over-current relay are given as a curve of (T) versus (M), where $\mathrm{M}$ (multiple of pickup current) is the ratio of the relay current, (I), to the pickup current value, (IP) $[8,9]$.

$$
\mathrm{T}=\mathrm{TDS} \times \frac{\alpha}{\mathrm{M}^{\beta}-1} \text { and, } \mathrm{M}=\frac{\mathrm{I}}{\mathrm{I}_{\mathrm{P}}}
$$

where, $\alpha$ and $\beta$ are constants depending on the type of selected characteristics.

Table 1. Different type of IDMT characteristics cures

\begin{tabular}{lcc}
\hline \multicolumn{1}{c}{ Relays characteristic } & $\alpha$ & $\beta$ \\
\hline Standard inverse (SI) & 0.14 & 0.02 \\
Very inverse (VI) & 13.5 & 1 \\
Extremely inverse (EI) & 80 & 2 \\
Long time inverse (LTI) & 120 & 1 \\
\hline
\end{tabular}




\subsection{Backup-primary constraint}

Each relay's pickup current has minimum and maximum values as shown in (3). These values are chosen to be 1.2 and 2 times the maximum load current which is seen by each relay in a normal operation. Similarly, the time delay setting has minimum and maximum limits based on the relay's current-time characteristic. The minimum and maximum TDS are assumed to be 0.05 and 1.2 respectively in all over studies [10].

$$
\begin{aligned}
& T D S_{i}^{\min } \leq T D S_{i} \leq T D S_{i}^{\max } \\
& I_{P i}^{\min } \leq I_{P i} \leq I_{P i}^{\max }
\end{aligned}
$$

The minimum pickup current setting of the relay $\left(I_{P i}^{\min }\right)$ is the maximum value between the minimum available current setting and the maximum load current $\max \left(I_{\text {load }} i^{\max }, I_{P i}^{\min }\right)$. In similar, the maximum pickup current setting $\left(I_{P i}^{\max }\right)$ is chosen as the minimum value between the maximum available current setting of the relay and the minimum measured fault current $\max \left(I_{F a u l t} i^{\min }, I_{P i}^{\max }\right)$ [11]. In order to coordinate two over-current relays, one as main (primary) relay (i) and the other as backup relay (j), the difference between the operating time of backup relay and main relay should be more than the CTI(Coordination Time Interval). So the constraints for coordination of over-current relays $i$ and $j$ will be in the form of inequality (4) [12]:

$$
T_{j}^{K}-T_{i}^{K} \geq C T I
$$

$\mathrm{T}_{\mathrm{j}}^{\mathrm{K}}$ and $\mathrm{T}_{\mathrm{i}}^{\mathrm{K}}$ : are respectively the operation time of backup and primary relay for a short circuit in $\mathrm{k}$. CTI is the time interval for coordination of primary and backup relay and it can take a value between 0.2 and 0.5 seconds, it depends on the type of relays, generally taken as $0.3 \mathrm{sec}$ [13. 14].

\section{APPLICATION OF DUAL SIMPLEX METHOD}

Linear programming is one of the various techniques of optimization. It refers to modeling and solving a problem mathematically that involves the economic allocation of limited resources by choosing a particular course of action among various alternatives to achieve the desired accuracy [15]. Dual simplex method is a variant of regular simplex method, developed by Lemke, to solve a LPP. It starts from infeasible solution to the primal. The method works in an iterative manner such that it forces the solution to become feasible as well as optimal at some stage [16].

\subsection{Problem formulation}

The total time objective function in (5), for $\mathrm{N}$ primary relay is minimized, subject to various constraints (2) and (3). These constraints are relay setting constraints and backup-primary relay constraints:

$$
\min \sum_{\mathrm{i}=1}^{\mathrm{N}} \mathrm{T}_{\mathrm{i}, \mathrm{K}}
$$

where $\mathrm{N}$ is the number of relays, $\mathrm{T}_{\mathrm{i}, \mathrm{k}}$ is the operating time of the relay $\mathrm{R}_{\mathrm{i}}$, for fault in zone $\mathrm{k}$.

\subsection{Relay characteristics}

In this paper the DOCR's are assumed to have normal IDMT characteristic as comply with the IEC60255-3 standard. The characteristics of the DOCR are given as a curve of T versus M, where, i.e.

$$
\mathrm{M}=\frac{\mathrm{I}}{\mathrm{I}_{\mathrm{P}}}
$$

where $\mathrm{M}$ is a multiple of the pickup current. $\mathrm{I}$ is the relay current (overload or fault current) and $\mathrm{I}_{\mathrm{P}}$ is the pickup current. From (1) one can see that the relation between the operating time $\mathrm{T}$ and the multiple pickup current $\mathrm{M}$, is nonlinear. Since the multiple pickup current of the relays can be predetermined, so for a fixed $\mathrm{M},(1)$ becomes linear as follows:

$$
t=a * T D S
$$

where;

$$
a=\frac{0.14}{\left(\frac{I}{I_{p}}\right)^{0.02}-1}
$$


by substitution from (8) in (1), the objective function becomes;

$$
\min \sum_{\mathrm{i}=1}^{\mathrm{N}} \mathrm{a}_{\mathrm{i}} \times \mathrm{TDS}_{\mathrm{i}}
$$

Formula (9) is optimized using LP-dual simplex method [16] subject to the condition that the operation of the backup relays remains properly coordinated.

\section{CASE STUDIES}

In this paper IEEE 33-bus radial distribution test feeder is considered for optimum relay coordination between primary and backup directional over-current relays in presence of two emplacements of renewable energy sources. The operating voltage is $12.66 \mathrm{kV}$. Directional over-current relays are used in the system to protect the feeder in case of three phase faults. The single line diagram of the IEEE 33-bus system is presented in Figure $1[17,18]$. The model is simulated in MATLAB software without and with renewable energy sources to calculate the optimal setting of DOCRs using dual simplex method under system changes. The program is implemented for two emplacements of renewable energy sources. Three phase faults are generated on each bus.

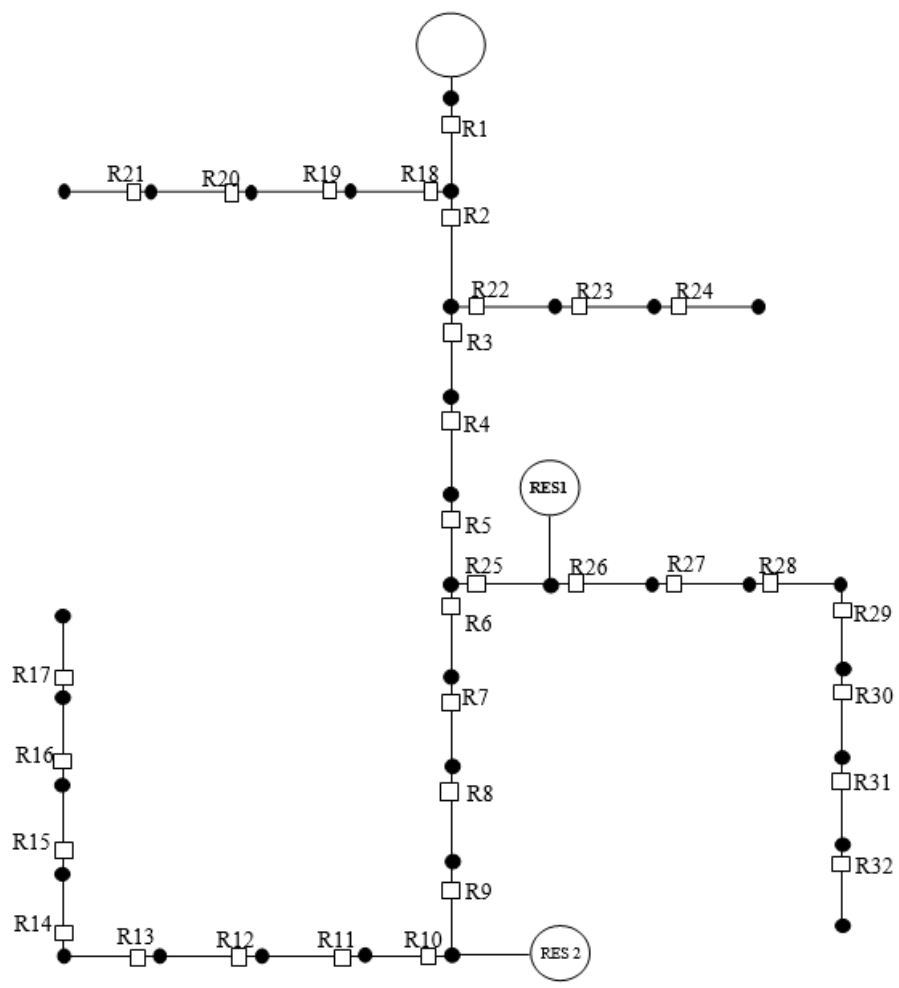

Figure 1. Power distribution system of the IEEE 33-bus system under study

\section{RESULTS AND DISCUSSION}

The main contributions of this paper are using the optimization technique to find optimal relay settings (TDSs), solve the linear problem of DOCRs with the system changed topology. Installing RESs leads to placing impedance in parallel with a part of network; therefore the impedance seen at fault location is reduced, the presence of RESs will change the normal power flow as well as the fault current, which are not restricted to the connected bus. The relay coordination problem is solved as optimization problem and optimised relay settings are obtained with standard time inverse DOCRs relays.

In order to minimize the objective function in (5), the best global positions (TDS) are calculated using dual simplex algorithm. Throughout the calculations, the pick-up currents are kept constant $(\mathrm{Ip}=1)$. The IDMT standard inverse (SI) curve is assumed for all calculations. Table 2 shows the optimized TDS values for different relays involved in coordination for the network before connecting the RESs. These values were obtained during coordination process. 
Table 2. Optimal TDSs with RESs

\begin{tabular}{ccc}
\hline \multirow{2}{*}{ Relays } & \multicolumn{2}{c}{ TDSs for $(\mathrm{Ip}=1)$} \\
\cline { 2 - 3 } R_1 & Without RESs & With RESs \\
\hline R_2 & 0.675663 & 0.670406 \\
R_3 & 0.353419 & 0.448362 \\
R_4 & 0.318309 & 0.318034 \\
R_5 & 0.304144 & 0.309247 \\
R_6 & 0.274135 & 0.281219 \\
R_7 & 0.143893 & 0.255640 \\
R_8 & 0.183217 & 0.123048 \\
R_9 & 0.154617 & 0.153524 \\
R_10 & 0.163167 & 0.161653 \\
R_11 & 0.096253 & 0.113031 \\
R_12 & 0.136368 & 0.089085 \\
R_13 & 0.157917 & 0.136354 \\
R_14 & 0.071023 & 0.156935 \\
R_15 & 0.062127 & 0.070195 \\
R_16 & 0.166054 & 0.061512 \\
R_17 & 0.478715 & 0.155771 \\
R_18 & 0.596469 & 0.439360 \\
R_19 & 0.541619 & 0.424051 \\
R_20 & 0.260460 & 0.340930 \\
R_21 & 0.750357 & 0.229842 \\
R_22 & 0.238622 & 0.598877 \\
R_23 & 0.179890 & 0.254837 \\
R_24 & 0.426788 & 0.216386 \\
R_25 & 0.372167 & 0.454004 \\
R_26 & 0.555465 & 0.137460 \\
R_27 & 0.261937 & 0.255056 \\
R_28 & 0.163131 & 0.199023 \\
R_29 & 0.148502 & 0.203094 \\
R_30 & 0.223147 & 0.220710 \\
R_31 & 0.186814 & 0.321115 \\
R_32 & 0.615710 & 0.147084 \\
\hline & & 0.234190 \\
\hline
\end{tabular}

Table 2 shows the values of TDSs calculated to be used in the adaptive coordination after connecting RESs at bus 26 and at bus 10 respectively. Comparing the values of TDSs got in the coordination before connecting the RESs and the values of TDSs got after connecting the RESs using adaptive protection scheme, it was seen that if the operating time of the relay is reduced due to increase in fault current seen by that relay, its TDSs value need to be increased in order to maintain the operating time as it was before connecting the RESs. Similarly, if the operating time of the relay is increased due to decrease in fault current which seen by that relay, its TDSs value need to be decreased in order to maintain the operating time as it was before connecting the RESs. In general, it is observed that there is remarkable improvement in their TDS of relays in presence of RESs in the distribution system. The increase in the fault current decreased the operating time for the relays located downstream from the faulted bus and increase the operating time for the relays between the substation and RESs.

\section{CONCLUSION}

In this paper the authors proposed the dual simplex method to solve the problem of coordination of DOCR's relays in presence of renewable energy sources in the distribution system. The results prominently show effectiveness of linear programming optimization for designing optimum protection scheme for radial distribution systems in presence of renewable energy sources using DOCRs. Furthermore, we propose, in the future work, the application optimization techniques to find the optimal TDS and Ip for DOCRs in distribution system in the presence of renewable energy sources. Based on the coordination results obtained in this research, the proposed dual simplex optimization algorithm can be used to calculate the settings of the directional overcurrent relays in a distribution network with distributed generation.

\section{REFERENCES}

[1] IEEE, "Smart grid: Reinventing the electric power system," IEEE Power \& Energy Society (PES) USA, 2012

[2] R. M. Chabanloo, H. A. Abyaneh, A. Agheli, and H. Rastegar, "Overcurrent relays coordination considering transient behaviour of fault current limiter and distributed generation in distribution power network," in IET Generation, Transmission \& Distribution, vol. 5, no. 9, pp. 903-911, September 2011. 
[3] S. V. Khond and G. A. Dhomane, "Optimum coordination of directional overcurrent relays for combined overhead/cable distribution system with linear programming technique," Protection and Control of Modern Power Systems, vol. 4, article no. 9, pp. 1-7, 2019.

[4] L. Bougouffa and A. Chaghi, "Impact of distributed generation and series FACTS compensator on directional overcurrent protection coordination," International Journal of Hybrid Information Technology, vol. 7, no. 4, pp. 299-308, 2014.

[5] L. Bougouffa and A. Chaghi, "Investigation of TCSC controller and distributed generation effects on IDMT directional overcurrent relay in distribution system," Procedia Soc. and Behav. Sci., vol. 195, pp. 2421-2429, 2015.

[6] B. Abdi, M. Abroshan, M. H. As linezhad, and A. Alimardani, "Coordination return of protective devices in distribution systems in presence of distributed generation," Energy Procedia, vol. 12, pp. 263-270, 2011.

[7] H. Zayandehroodi, A. Mohamed, H. Shareef, and M. Mohammad Jafari, "Impact of distributed generations on power system protection performance," International Journal of Physical Sciences, vol. 6, no. 16, pp. 3999-4007, August 2011.

[8] "Network protection \& automation guide," AREVA, Paris, France, T\&D Ltd, 2002.

[9] H. H. Zeineldin, E. F. El-Saadany, and M. M. A. Salama, "Optimal coordination of over current relays using a modified particle swarm optimization," Electric Power Systems Research, vol. 76, no. 11, pp. 988-995, 2006.

[10] H. Javadi, S. M. A. Mousavi, and M. Khederzadeh, "A novel approach to increase FCL application in preservation of over-current relays coordination in presence of asynchronous DGs," International Journal of Electrical Power and Energy Systems, vol. 44, no. 1, pp. 810-815, 2013.

[11] M. Jazaeri and M. Cholamzadeh, "Considering the effect of series capacitor in optimal coordination of directional overcurrent relays, trends in applied sciences research," Trends in Applied Sciences Research, vol. 7, no. 6, pp. 421-433, 2012.

[12] D. Vijayakumar and R. K. Nema, "Superiority of PSO relay coordination algorithm over non-linear programming: A comparison, review and verification," 2008 Joint International Conference on Power System Technology and IEEE Power India Conference, New Delhi, pp. 1-6, 2008.

[13] M. Ezzeddine and R. Kaczmarek, "A novel method for optimal Coordination of directional overcurrent relays considering their available discrete settings and several operation characteristics," Electric Power Systems Research, vol. 81, no. 7, pp. 1475-1481, 2011.

[14] Panigrahi B. K., Manohar Singh, and A. R. Abhyankar, "Optimal coordination of directional over-current relays using teaching learning-based optimization (TLBO) algorithm," International Journal of Electrical Power and Energy System, vol. 50, pp. 33-41, 2013.

[15] P. P. Bedekar, S. R. Bhide, and V. S. Kale, "Optimum coordination of over-current relays in distribution system using dual simplex method," 2009 Second International Conference on Emerging Trends in Engineering \& Technology, Nagpur, pp. 555-559, 2009.

[16] A. Kartikeya Sarma and K. Mahammad Rafi, "Optimal selection of capacitors for radial distribution systems using plant growth simulation algorithm," International Journal of Advanced Science and Technology, vol. 2, no. 2, pp. 61-86, 2011.

[17] L. Bougouffa and A. Chaghi, "Optimal coordination of DOCR for radial distribution systems in presence of TCSC," International Journal of Power Electronics and Drive System (IJPEDS), vol. 7, no. 2, pp. 311-321, June 2016.

[18] L. Bougouffa and A. Chaghi, "Dual Simplex Method for Optimal Coordination of DOCR's in Distribution System with D-FACTS," International Journal of Information Science \& Technology, vol. 3, no. 3, pp. 3-9, 2019.

\section{BIOGRAPHIES OF AUTHORS}

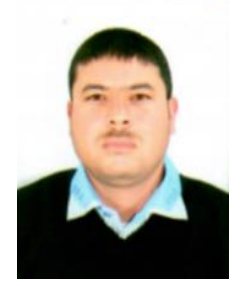

Dr. Lazhar Bougouffa was born in Batna, Algeria, 1986. He received his MASTER degree in Electrical Engineering from department of Electrical Engineering at University of Batna, Algeria, 2011, and received his Doctorate from Batna University, Algeria 2016. He is currently a lecturer of Department of Electrical Engineering at Faculty of Technology El-Oued University, and member LSP-IE research laboratory at Faculty of Technology-University of Batna. His areas of interest include power system protection, power systems optimization, power quality and FACTS devices.

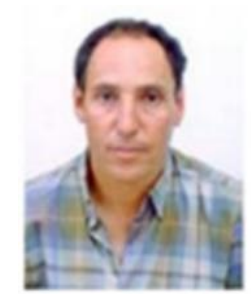

Prof. Abdelaziz Chaghi was born in Batna, Algeria, 1954. He received his BS degree from the University of Oran, Algeria 1980, and MS from the Manchester University, En gland 1984, and received his $\mathrm{PhD}$ from Batna University, Algeria 2004. He is currently a Professor at Department of Faculty of Technology, Electrical Engineering and member LSP-IE research laboratory at Faculty of Technology-University of Batna. His areas of interest include power systems optimization, power system protection, renewable energy sources, harmonic, power quality and FACTS devices. 